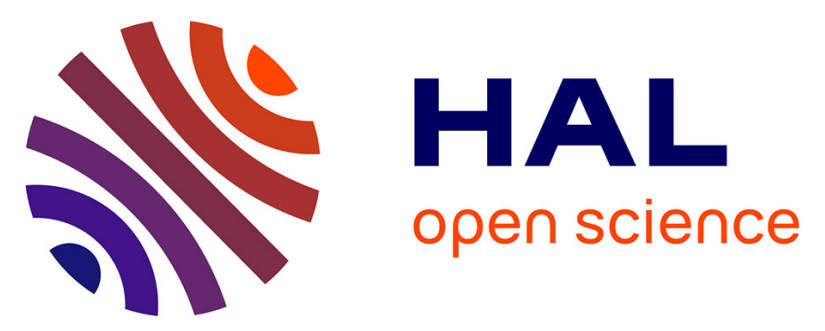

\title{
Building responsive materials by assembling Fe4Co4 switchable molecular cubes
}

Qui Pham Xuan, Jana Glatz, Amina Benchohra, Juan-Ramón Jiménez, Rémi Plamont, Lise-Marie Chamoreau, Alexandrine Flambard, Yanling Li, Laurent Lisnard, Damien Dambournet, et al.

\section{To cite this version:}

Qui Pham Xuan, Jana Glatz, Amina Benchohra, Juan-Ramón Jiménez, Rémi Plamont, et al.. Building responsive materials by assembling $\mathrm{Fe} 4 \mathrm{Co} 4$ switchable molecular cubes. Journal of Materials Chemistry C, In press, 10.1039/D1TC01825F . hal-03275386

\section{HAL Id: hal-03275386 https://hal.sorbonne-universite.fr/hal-03275386}

Submitted on 1 Jul 2021

HAL is a multi-disciplinary open access archive for the deposit and dissemination of scientific research documents, whether they are published or not. The documents may come from teaching and research institutions in France or abroad, or from public or private research centers.
L'archive ouverte pluridisciplinaire HAL, est destinée au dépôt et à la diffusion de documents scientifiques de niveau recherche, publiés ou non, émanant des établissements d'enseignement et de recherche français ou étrangers, des laboratoires publics ou privés. 


\title{
Building responsive materials by assembling $\left\{\mathrm{Fe}_{4} \mathrm{Co}_{4}\right\}$ switchable molecular cubes
}

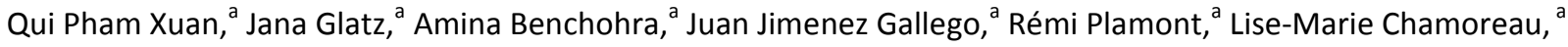 \\ Alexandrine Flambard, ${ }^{a}$ Yanling Li, ${ }^{a}$ Laurent Lisnard, ${ }^{a}$ Damien Dambournet, ${ }^{\mathrm{b}, \mathrm{c}}$ Olaf J. Borkiewicz, ${ }^{\mathrm{d}}$ Marie-Laure \\ Boillot, ${ }^{e}$ Laure Catala, ${ }^{e}$ Antoine Tissot ${ }^{f}$ and Rodrigue Lescouëzec* ${ }^{* a}$
}

Responsive materials that can answer to chemical or physical external stimuli offer numerous prospects in material science. Here, we have elaborated a two-step synthetic approach that allows incorporating molecular cubic switches into a polymeric material. Firstly, a preformed half-capped, $\mathrm{Cs}^{+}$-templated $\left\{\mathrm{Fe}_{4} \mathrm{CO}_{4}\right\}$ cyanido-polymetallic cubic unit ("pro-cube") is obtained and proven to be stable in solution, as demonstrated by paramagnetic NMR. Secondly, the reaction of the pro-cube with a ditopic scorpionate ligand enables the precipitation of a polymeric network containing the cubic unit. Furthermore, the adequately chosen ditopic ligand that coordinates the Co ions of the pro-cube allows us to preserve the switchable properties of the cubic unit. Indeed, the magnetic properties of the polymeric material compare well with those of the molecular cubic model that is obtained by reacting a non-bridging scorpionate ligand, and that was prepared as a reference. Both the polymeric material and the molecular model cube show a thermally-induced metal-metal electron transfer near room temperature. Interestingly, the magnetic state of the polymeric material is shown to depend on its hydration state, indicating its capability to act as a chemo-sensor.

\section{Introduction}

The design of responsive materials capable of changing their physical properties upon exposure to external, chemical or physical stimuli is an active topic in material science with numerous potential applications such as in sensors, information storage and medical science. ${ }^{[1-4]}$ A possible approach for synthesizing such materials consists in using metal-based complexes that can be reversibly switched between two different electronic states, associated with different physical behaviours. A prominent class of molecular switches are the spin-crossover (SCO) complexes that undergo a spin-state change under the application of different stimuli (light, temperature, pressure, etc.). ${ }^{[5-9]}$ In particular, octahedral Fe(II) SCO complexes showing radical changes in their optical, magnetic and dielectric properties due to the reversible conversion between the ${ }^{1} \mathrm{~A}_{1 \mathrm{~g}}\left(\mathrm{t}_{2 \mathrm{~g}}{ }^{6}\right)$ and ${ }^{5} \mathrm{~T}_{2 \mathrm{~g}}\left(\mathrm{t}_{2 \mathrm{~g}}{ }^{4} \mathrm{e}_{\mathrm{g}}{ }^{2}\right)$ states, have attracted strong attention. ${ }^{[8,10,11]}$ The common strategy to design responsive materials based on SCO complexes consists in reacting metal ions with bridging ligands that induce an adequate ligand field in order to observe a spin-crossover phenomenon. For example, the simple reaction of $\mathrm{Fe}(\mathrm{II})$ metal salts with the triazolyl ligand ( $\mathrm{Tz}$ ) leads to the one-dimensional (1D) polymer material

\footnotetext{
a. Sorbonne Université, CNRS, Institut Parisien de Chimie Moléculaire, F-75005 Paris, France

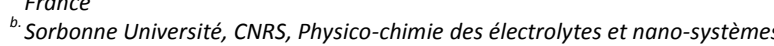
interfaciaux, PHENIX, F-75005 Paris, France

Réseau sur le Stockage Electrochimique de l'Energie (RS2E), FR CNRS 3459, 80039 Amiens, France

${ }^{d .} X$-ray Science Division, Advanced Photon Source, Argonne National Laboratory, 9700 South Cass Avenue, Argonne, Illinois 60439, United States

e. Université Paris-Saclay, CNRS, Institut Chimie Moléculaire et Matériaux d'Orsay, 91405, Orsay, France

f. Institut des Matériaux Poreux de Paris, Ecole Normale Supérieure, ESPCI Paris, CNRS, PSL University, 75005, Paris, France

† Footnotes relating to the title and/or authors should appear here.

Electronic Supplementary Information (ESI) available: [details of any supplementary information available should be included here]. See DOI: 10.1039/x0xx00000x
}

$\left[\mathrm{Fe}^{\prime \prime}(\mathrm{Tz})_{3}\right]_{\mathrm{n}}$ showing magnetic and optical bistability near room temperature. ${ }^{[12]}$ More sophisticated strategies leading to functional materials have also been explored. For instance, the reaction of poly-cyanometallates in conjunction with pyridyl ligands and $\mathrm{Fe}(\mathrm{II})$ salts was used to design 2D or 3D frameworks showing switchable properties. ${ }^{[13]}$ Interestingly, Real et coll. showed that this strategy allows synthesizing porous materials that show interesting chemosensing properties thanks to the remarkable sensitivity of the SCO centres to their chemical surrounding. ${ }^{[14-17]}$ The cyanido-bridged charge transfer (CT) complexes that can be switched between two electronic states represent another interesting class of molecular switches, which share many features with SCO complexes. ${ }^{[18-21]}$ The FeCo Prussian blue analogues (PBA) were the first switchable charge transfer systems to be reported. ${ }^{[22]}$ In these coordination polymers, light irradiation, temperature change or pressure variation allow converting $\mathrm{Fe}^{\mathrm{IIS}}{ }_{\mathrm{LO}} \mathrm{CO}^{\mathrm{III}}{ }_{\mathrm{LS}}$ diamagnetic pairs into $\mathrm{Fe}^{\mathrm{III}}{ }_{\mathrm{LS}^{-}}$ CO ${ }_{\text {HS }}$ paramagnetic ones, leading to drastic changes in the magnetic properties of the solids. ${ }^{[23-26]}$ These purely inorganic coordination polymers are readily obtained by reacting hexa-cyanometallates with metal salts. Overall, in the above examples, the responsive materials are obtained by using monometallic cyanido complexes to lead to $2 \mathrm{D}$ or $3 \mathrm{D}$ coordination polymers. The use of preformed polymetallic cyanido-based building units (BU) has been scarcely explored. However, some works showed that this strategy could lead to the preparation of cyanide coordination polymers with large voids or porosity. ${ }^{[27-30]}$ For example, Long et al. showed that the reaction of octahedral cyanido clusters, $\left[\operatorname{Re}_{6} \mathrm{Se}_{8}(\mathrm{CN})_{6}\right]^{4-}$, leads to three-dimensional coordination polymers described as "expended PBA" and showing enhanced ion intercalation properties. ${ }^{[31]}$ Interestingly, Nihei, Oshio et al. recently used an elegant supramolecular approach to design responsive molecular materials by assembling $\left\{\mathrm{Fe}_{2} \mathrm{CO}_{2}\right\}$ switchable $\mathrm{CT}$ complexes through donoracceptor hydrogen-bond interactions. ${ }^{[32-34]}$ However, in these cases the resulting responsive materials are fragile as the switchable FeCo complexes are linked by weak supramolecular interactions. The use of polymetallic building units is much more common in the field of 
metal-organic frameworks ("MOFs"), where the so-called "secondary building units" (SBU) are generally formed in-situ during the reaction. ${ }^{[35,36]}$ Inspired by these examples and in search of new routes to form robust responsive materials that are able to interact with their surroundings, we decided to explore an original synthetic approach based on the assembly of polymetallic FeCo CT complexes that could be covalently linked to each other through rigid organic linkers in order to obtain stable networks. Among the large variety of FeCo switchable charge transfer complexes, we selected the cubic cyanide-bridged complexes of general formula $A \subset$ $\left.\left[\mathrm{Fe}(\mathrm{Tp})(\mathrm{CN})_{3}\right]_{4}[\mathrm{Co}(\mathrm{RTp})]_{4}\right\}$ (abbreviated $\mathrm{A} \subset\left\{\mathrm{Fe}_{4} \mathrm{CO}_{4}\right\}$ ). In these cubic molecules, $\mathrm{A}$ is an inserted alkali ion, the edges are built of cyanide bridges while tris(pyrazol-1-yl)borates anions (Tp and RTp, $R$ being a functional group) act as blocking ligands to prevent polymerization. Beside showing both photo- and thermo- induced electron transfer, these cubes also show remarkable redox properties: they exhibit up to nine reversibly accessible redox states associated with electrochromic properties. ${ }^{[37-40]}$ More importantly, these cubes are soluble molecular models of the FeCo PBA and can be extremely stable in solution, making them ideal building units for the design of high dimensionality polymers. We thus present here our first results in the design of cube-based responsive polymers.

\section{Results and discussion}

Synthesis of the molecular cubic model and cube-based network.

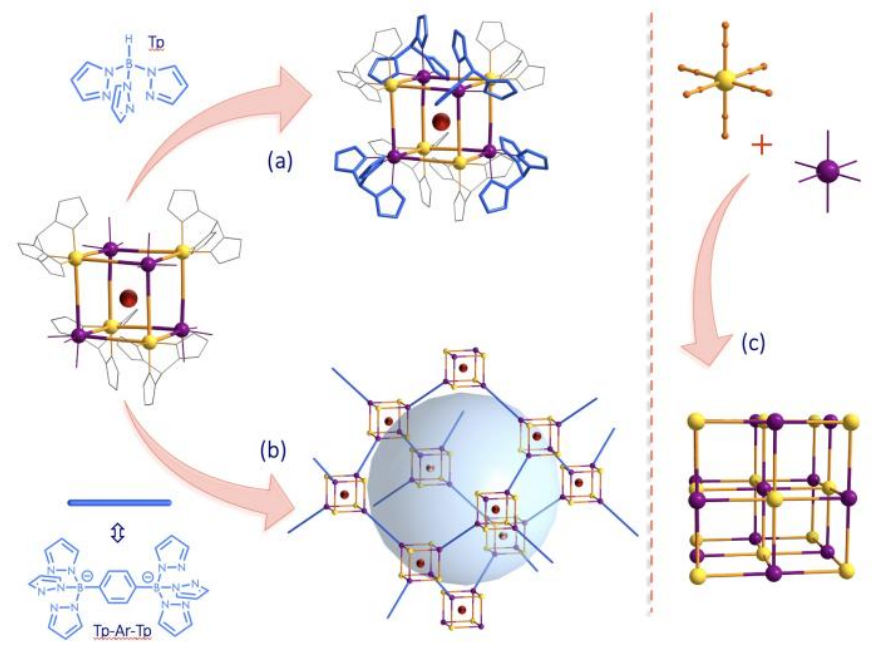

Scheme 1. Synthetic pathways of (a) the molecular cubic switch, (b) the cube-based network and, (c) a Prussian blue analogue.

Most of the cyanido $A \subset\left\{\mathrm{Fe}_{4} \mathrm{M}_{4}\right\}$ cubic complexes (M=Mn, Fe, Co, $\mathrm{Ni}$ ) that we previously reported can be obtained in a one pot synthesis ${ }^{[38,40-43]}$ by reacting all the subcomponents together at room temperature: the $\left[\mathrm{Fe}^{\prime \prime \prime}(\mathrm{Tp})(\mathrm{CN})_{3}\right]^{-}$complex, a divalent metal salt of $\mathrm{M}$, an alkali salt and the RTp anionic blocking ligand. However, such a one pot reaction is not always successful or does not give the best yield. For example, in the case of the $\operatorname{Cs} \subset\left\{\mathrm{Fe}_{4} \mathrm{Mn}_{4}\right\}$ cubic complex one needs to form a pro-cube $A \subset\left\{\left[\mathrm{Fe}^{\prime \prime \prime}(\mathrm{Tp})(\mathrm{CN})_{3}\right]_{4}\left[\mathrm{Mn}(\mathrm{S})_{3}\right]_{4}\right\}$ (S = solvent) that is further reacted with a RTp blocking ligand. ${ }^{[40]}$ The nature of the solvent was proven to be critical in the pro-cubes and cube's synthesis as well as the reactants' concentrations. Lower concentrations were shown to favour the cube's dissociation and the precipitation or crystallization of undesired polymeric coordination phases. For instance, at low concentration the known cyanide-bridged chain compound of formula $\left\{\left[\mathrm{Fe}^{\prime \prime \prime}(\mathrm{Tp})(\mathrm{CN})_{3}\right]_{2}\left[\mathrm{M}^{\prime \prime}(\mathrm{S})_{2}\right]\right\}$ (S = solvent $)^{[44]}$ can be obtained as a side-product. Interestingly, our previous studies showed that the introduction of $\mathrm{Cs}^{+}$as a templating ion confers a higher stability to the $\left\{\mathrm{Fe}_{4} \mathrm{CO}_{4}\right\}$ cube and allows its synthesis with higher yield. ${ }^{[38]}$ Considering these previous results, a step-by-step strategy was adopted in the present work. Thus, Cs-based procubes were formed in a first stage by reacting all precursors (except the blocking ligand, $\mathrm{Tp}^{-}$) in an adequate solvent. This should guarantee the stability of the cubic nodes during the network assembly. The stability of the octametallic building units was checked by ${ }^{1} \mathrm{H}$ and ${ }^{133} \mathrm{Cs}$ NMR spectroscopy (Fig. 3 and SI). Once formed, these pro-cubes were connected to each other by using a polytopic organic linker of the $\mathrm{Tp}^{-}$family, the Tp-Ar-Tp ligand depicted in scheme 1 . This strategy allows avoiding the precipitation of undesired polymeric species such as the neutral $\{\mathrm{Co}(\mathrm{Tp}-\mathrm{Ar}-\mathrm{Tp})\}_{\mathrm{n}}$. The reaction leads to the desired material of formula $\quad \mathrm{Cs} \subset\left\{\left[\mathrm{Fe}(\mathrm{Tp})(\mathrm{CN})_{3}\right]_{4}\left[\mathrm{Co}_{4}(\mathrm{Tp}-\mathrm{Ar}-\mathrm{Tp})_{1.9}\right\}\right.$ 10DMF (see characterizations below) as a highly insoluble amorphous precipitate. All our attempts to slow down the reaction and to obtain crystalline products failed (e.g. H-tubes and crystallization in silica gels). It is worth noticing that a significant colour change occurs during the reaction of the pro-cube with the bridging Tp-ArTp ligand (detailed in experimental part), which is also observed when reacting the pro-cube with the Tp blocking ligand forming the new molecular model $\mathrm{Cs} \subset\left\{\left[\mathrm{Fe}(\mathrm{Tp})(\mathrm{CN})_{3}\right]_{4}[\mathrm{Co}(\mathrm{Tp})]_{4}\right\}$ (see ESI). This colour change from red to deep green accounts for the occurrence of a metal-metal electron transfer during the synthesis where some $\mathrm{Fe}^{\prime \prime \prime}-\mathrm{CN}-\mathrm{Co}$ " pairs are being converted into $\mathrm{Fe}^{\text {II }}-\mathrm{CN}-\mathrm{Co}^{\text {III }}$ ones. Indeed, $\mathrm{Fe}^{\prime \prime} \mathrm{Co}{ }^{\text {III }}$ pairs present an intense charge transfer transition near 800 $\mathrm{nm}$ while Co" $\mathrm{Fe}$ "I' pairs present a charge transfer transition near 500 $n m .{ }^{[45]}$ Here, the substitution of the DMF solvent molecules by the $\mathrm{Tp}$ anionic ligand induces a stronger ligand-field that is expected to favour the Co ${ }^{\text {III }}$ oxidation state. Such phenomenon was already reported in a previous study where the reaction of pzTp blocking ligand $(p z T p=$ tetra(pyrazolyl)borate anionic ligand) with the red $\left\{\mathrm{Fe}^{\text {III }}{ }_{4} \mathrm{CO}_{4}{ }_{4}\right\}$ pro-cube led to a deep green $\mathrm{Cs} \subset\left\{\mathrm{Fe}^{\prime \prime}{ }_{4} \mathrm{Co}{ }_{3}{ }_{3} \mathrm{Co}\right.$ " $\}$ cubic complex. ${ }^{[38]}$ In this peculiar case, one of the cobalt remained in the +II oxidation state and the charge was balanced by the inserted alkali ion to yield a neutral cubic complex. Here, we observe a noticeable difference with our previous report. If the reaction of the pro-cube with $\mathrm{Tp}^{-}$does initially lead to the same $\mathrm{Cs} \subset\left\{\mathrm{Fe}_{4}{ }_{4} \mathrm{CO}^{\prime \prime \prime}{ }_{3} \mathrm{CO}^{\prime \prime}\right\}$ electronic state (as shown by the NMR data below), the cubic complex, which is more soluble in DMF than the pzTp-based analogue cubic complex, shows a slow oxidation over time in air. Therefore, depending on the crystallization conditions, the cube can be isolated in its neutral form $\mathrm{Cs} \subset\left\{\mathrm{Fe}_{4}{ }_{4} \mathrm{CO}^{\prime \prime \prime}{ }_{3} \mathrm{CO}^{\prime \prime}\right\}$ or in the fully oxidized $\mathrm{Cs} \subset\left\{\mathrm{Fe}_{4}{ }_{4} \mathrm{CO}^{\mathrm{III}}{ }_{4}\right\} \mathrm{ClO}_{4}$ form as a perchlorate salt (see below). This observation indicates that the electronic state of the polymeric material obtained by the reaction of the $\left\{\mathrm{Fe}_{4} \mathrm{CO}_{4}\right\}$ pro-cube and the bridging ligand Tp-Ar-Tp should be carefully analysed. Thus, we first 
describe here the structural features of both the cubic model compound and the polymeric network. Then, by using a multitechnique approach, the electronic state of the materials is carefully characterized by the use of FT-IR, NMR, UV-vis spectroscopy and elemental analysis (based on atomic absorption and Energy Dispersive spectrometry). Finally, in the last section, we investigate to which extent the switchable properties of the molecular cubes can be transmitted to the polymeric material. In particular, we study the changes of the magnetic properties upon intercalation and deintercalation of water molecules into the amorphous framework.

\section{Structural characterization}

Suitable crystals for X-ray diffraction of the molecular model $\mathrm{Cs} \subset\left\{\left[\mathrm{Fe}^{\prime \prime}(\mathrm{Tp})(\mathrm{CN})_{3}\right]_{4}\left[\mathrm{Co}^{\prime \prime \prime}(\mathrm{Tp})\right]_{3}\left[\mathrm{Co}{ }^{\prime \prime}(\mathrm{Tp})\right]\right\} 14 \mathrm{CH}_{3} \mathrm{CN}_{2} \mathrm{O} \quad$ were obtained by slow evaporation of an acetonitrile solution (cubic model). The material crystalizes in the Pbca space group and the asymmetric unit is composed of only $1 / 2$ of the cube, which corresponds to a face of the cubic molecule. In other words, the Fe and $\mathrm{Co}$ are not discernible in the present case, neither are the $\mathrm{C}$ and $\mathrm{N}$ atoms of the cyanide bridges. The experimentally measured metal-cyanide bond lengths, $1.927(4) \AA$, thus represent an averaged value of the Fe- $\mathrm{C}$ and $\mathrm{Co}-\mathrm{N}$ distances. This averaged value is coherent with the occurrence of only one Co" ion per cube, which implies the presence of 21 metal-cyanide distances of approx. $1.9 \AA$ (the expected value for the $\mathrm{Co}^{\text {III }}-\mathrm{N}$ and $\mathrm{Fe}^{\text {II }}-\mathrm{C}$ bond lengths) ${ }^{[46,47]}$ and 3 other distances close to $2.09 \AA$ (the expected value for Co" $-\mathrm{N}$ bond lengths). ${ }^{[46,47]}$ The average Fe' Co distance, $5.000(2) \AA$, is slightly longer than the expected $\mathrm{Fe}^{\text {II }}-\mathrm{CO}^{\text {III }}$ value and coherent with that hypothesis. ${ }^{[24]}$ The presence of the $\mathrm{Co}{ }^{11}$ ion, is unambiguously proved by the solution ${ }^{133} \mathrm{Cs},{ }^{1} \mathrm{H}$ NMR spectra and magnetic measurements (see below and ESI) and coherent with the absence of counter-anion in the crystal structure.

Concerning the polymeric compound, the SEM images (see ESI) reveal that it precipitates as small anisotropic particles with long edges of ca $0.2 \mu \mathrm{m}$. X-ray diffraction analysis performed on the precipitate revealed the absence of long-range order with diffuse scattering characteristic of amorphous compounds. We used highenergy ( $\lambda=0.2116 \AA) X$-ray synchrotron experiments to measure total scattering data, which were Fourier transformed to obtain the pair distribution function (PDF). PDF represents the probability of finding a pair of atoms separated from a distance $r$. As a total scattering analysis, it can probe the short- and long-range order whatever the crystalline state of the material. ${ }^{[48,49]}$ For example, it was shown to be well-suited to study the local structure of MOFs. ${ }^{[50,51]}$ Figure 2 shows the PDFs of the polymeric compound and the cube model for comparison purpose along with the assignments of the inter-atomic distances $r$. Note that as an X-ray based technique, the signal scales with the atomic mass of the scattered element. At low $r$, the PDFs include the inter-atomic distances related to light organic moieties. The only substantial difference between the two samples is observed in that region with a broad and intense peak centred at $1.33 \AA$ for the cube model that is barely observed for the polymeric network. This peak corresponds to N-N, C-N and C-C distances and could arise in part from the acetonitrile solvent molecules within the crystal lattice. The polymeric network shows a distinct peak at $1.6 \AA$ enlisting B-N and $\mathrm{C}-\mathrm{C}$ and $\mathrm{C}-\mathrm{N}$ single bonds. Thereafter, two interatomic distances characteristic for metal-ligand bonds can be clearly distinguished: (i) one intense peak at $1.93 \AA$ assigned to $\mathrm{Fe}-\mathrm{C} / \mathrm{N}$ and $\mathrm{Co}(\mathrm{III})-\mathrm{N}$ bonds from the pyrazolyl ligands; ${ }^{[46,47]}$ (ii) one smaller peak at $2.22 \AA$, which clearly attests for the presence of $\mathrm{Co}(\mathrm{II})-\mathrm{N}$ bonds. This indicates that within the synthesis conditions, some cobalt ions are not oxidized. The broad intense peak centred at $3.03 \AA$ is assigned to different contributions: e.g. the interaction between the metal ions $(\mathrm{Co} / \mathrm{Fe})$ and the second neighbour atoms $(\mathrm{C} / \mathrm{N})$ of the cyanide ligand; the boron atom and the transition metals. The peak at 2.62 $\AA$ could account for the interaction between $\mathrm{C} / \mathrm{N}$ atoms and the transition metal from the perpendicular cubic edges. As we moved toward higher $r$ values, some peaks can be seen as the fingerprints of the cubic cage. The presence of an encapsulated $\mathrm{Cs}^{+}$ion is visible through its interaction with the $\mathrm{CN}$ bridges of the cubic edge that falls in the range of small peaks from 3.5 to $3.7 \AA$ (as observed for the molecular model cube). The distances between $\mathrm{Cs}^{+}$and the transition metals are in the range of 4.0-4.4 $\AA$. As previously shown, the $\mathrm{Cs}^{+}$atom is not necessarily in the exact centre of the cube. ${ }^{[38,40,52]}$ Moreover, Fe...Co distances corresponding to the edges of the cubic units are particularly visible with the intense peak located at $4.95 \AA$, while those arising from the cube face diagonal observed at around $7 \AA$, are barely detectable within the two samples. Finally, at higher $r$, the PDF fades as expected for short-range ordering. In conclusion, the pair distribution function clearly demonstrates that the cube integrity is maintained during the network self-assembly.

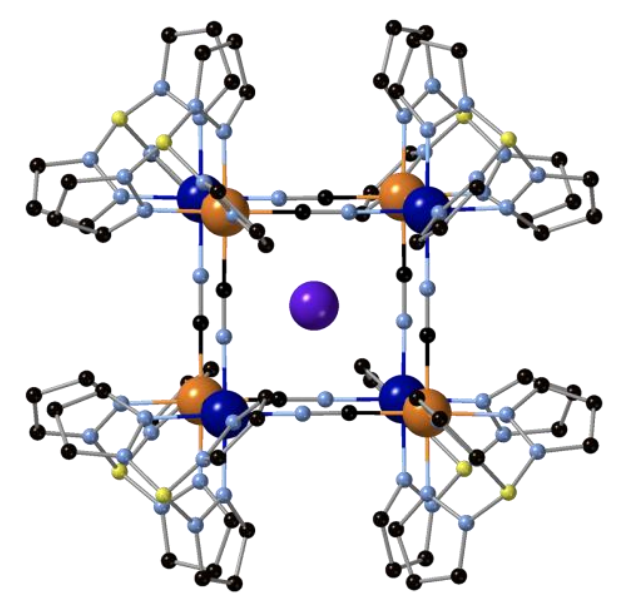

Figure 1. Perspective view of the XRD structure of the model paramagnetic cubic complex $\mathrm{Cs} \subset\left\{\left[\mathrm{Fe}{ }^{\mathrm{I}}(\mathrm{Tp})(\mathrm{CN})_{3}\right]_{4}\left[\mathrm{Co}^{\prime \prime \prime}(\mathrm{Tp})\right]_{3}[\mathrm{Co}(\mathrm{Tp})]\right\}$. C: grey, N: light blue, B: yellow, Fe: orange, $\mathrm{Co}$ : blue, $\mathrm{Cs}$ : violet. ( $\mathrm{H}$ atoms are omitted for clarity). 


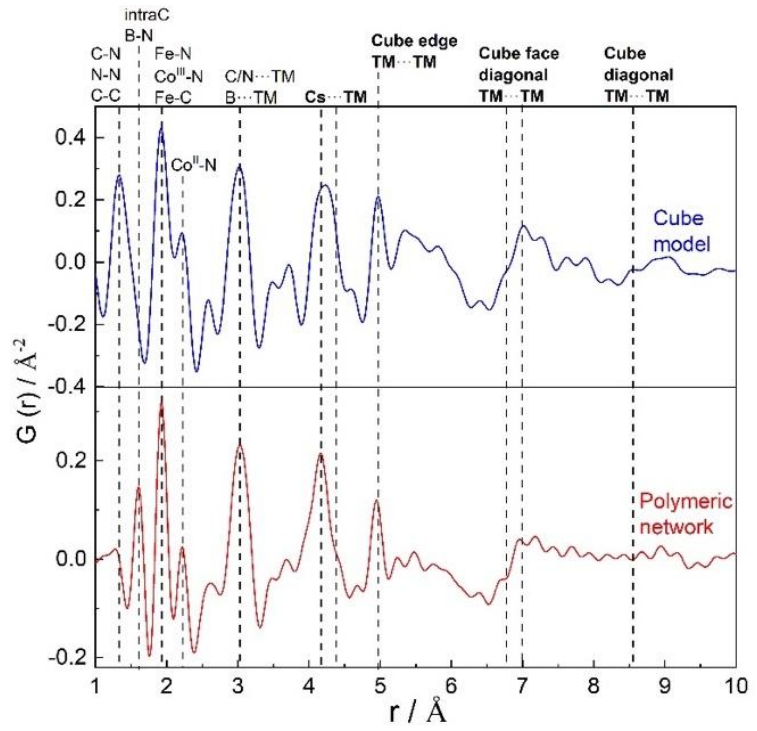

Figure 2. Pair distribution function analysis of the polymeric network (red) and of the model cube (blue); $r$ represents the interatomic distance.
The chemical composition of the polymeric network was checked by EDX analysis that indicates an Fe/Co ratio of approximately $1 / 1$, which is in agreement with a polymeric structure made of cubic units and an ideal composition of $\left(\mathrm{Cs} \subset\left\{\left[\mathrm{Fe}(\mathrm{Tp})(\mathrm{CN})_{3}\right]_{4}\left[\mathrm{Co}_{4}(\mathrm{TpArTp})_{2}\right]\right\}\right)_{\mathrm{n}}$. However, the combined results of elemental analysis and thermo-gravimetric experiments suggest that the DMF solvent molecules of the Co centres are not all replaced by the Tp-Ar-Tp bridging ligand. The material seems to precipitate betore a complete substitution occurs. Ihe elemental analysis is better in line with the following composition: $\left(\mathrm{Cs} \subset\left\{\left[\mathrm{Fe}(\mathrm{Tp})(\mathrm{CN})_{3}\right]_{4}\left[\mathrm{Co}_{4}(\mathrm{TpArTp})_{1.9}\right]\right\} 10 \mathrm{DMF}\right)_{n}$ that has been used in the magnetic study below.

\section{Characterization of the electronic state of the cubic units inside the polymeric network.}

In order to elucidate the electronic state of the metal ions in the cubic units contained in the polymeric material, various spectroscopic data have been collected and compared to the results obtained for the pro-cube and for model cubic units. Relevant FT-IR, UV-vis and NMR spectroscopic data are gathered in the Figure 3.

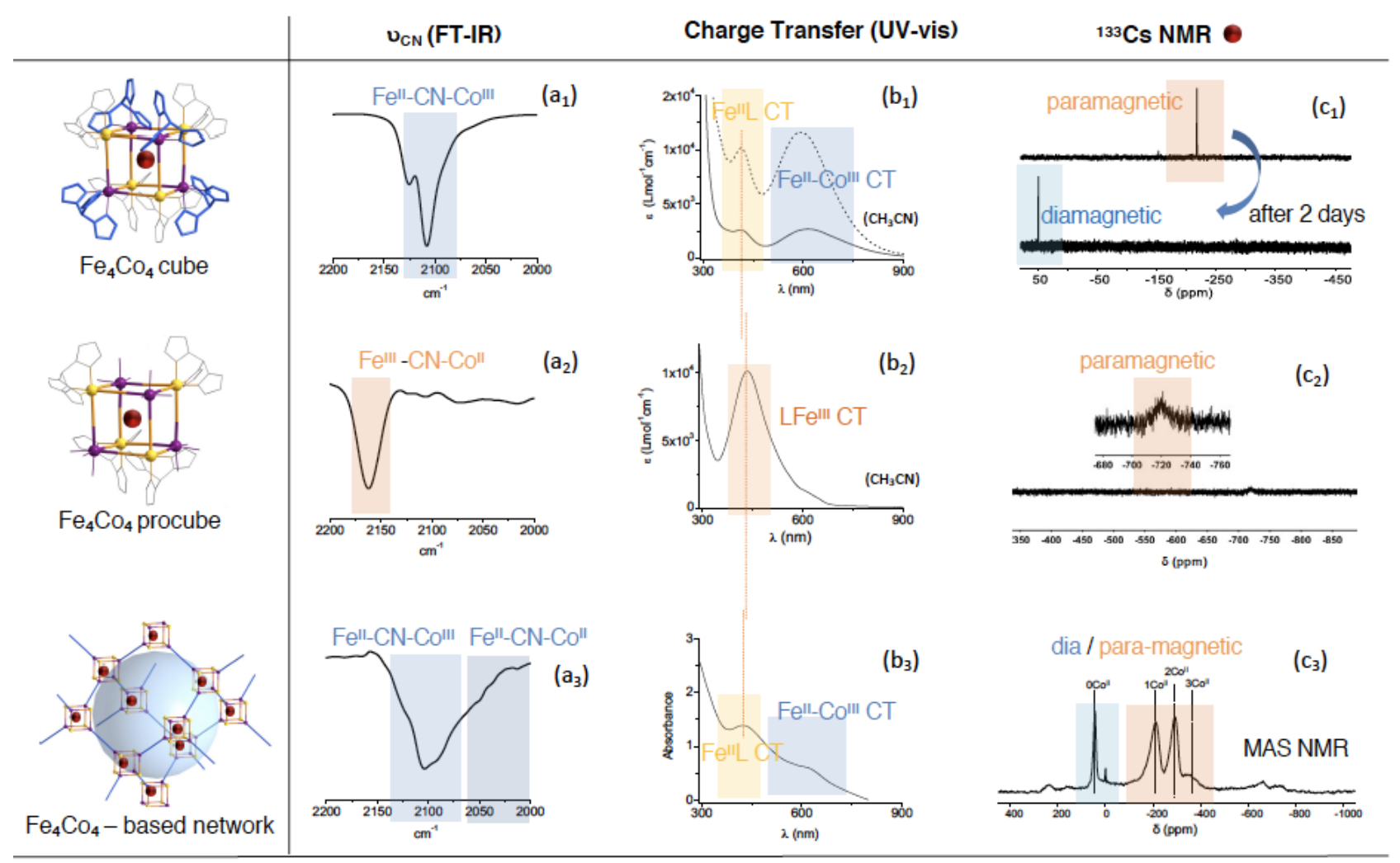

Figure 3. (a) FT-IR spectra (b) UV-vis spectra (c) ${ }^{133}$ Cs-NMR of 1 . The cubic model 2. The pro-cube and 3. The polymetallic network. The polymetallic network. Notes: $\left(b_{1}\right)$ diamagnetic cube in dotted line and paramagnetic cube in continuous line. b1 and b2 are solution UVvis measurements while b3 is a solid-state measurement; $c 1$ and c2 are solution NMR spectra while c3 is a solid-state MAS NMR ............. 
(a)

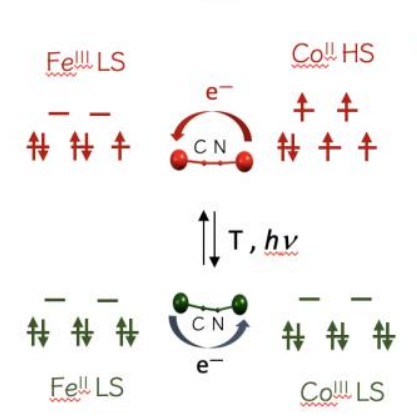

(b)

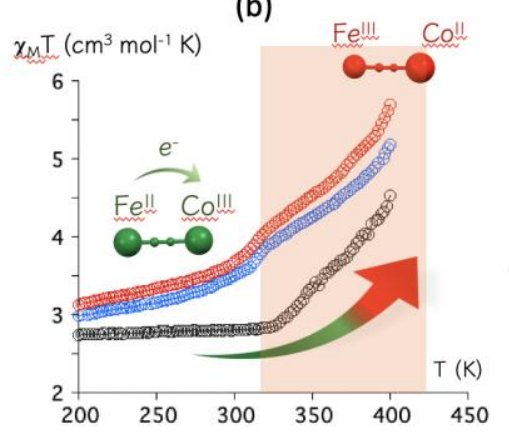

(c)

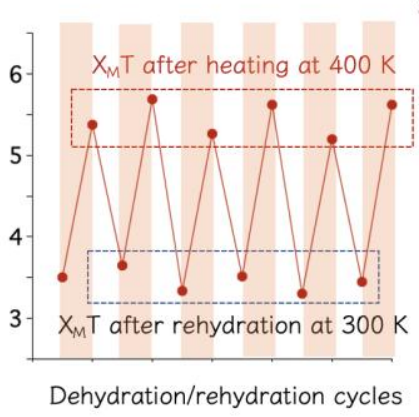

(d)

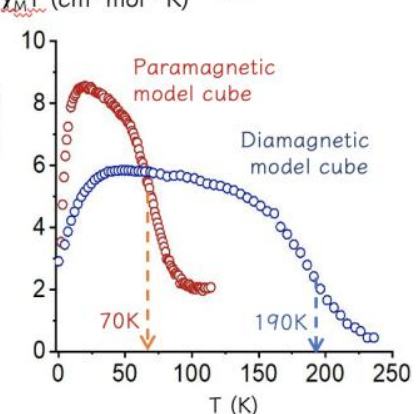

Figure 4. (a) Scheme of the electronic reorganisation occurring upon ETCST. (b) $\chi_{M} T$ versus T curves measured on : (i) freshly filtered crystals of the paramagnetic $\mathrm{Cs} \subset\left\{\mathrm{Fe}_{4}{ }_{4} \mathrm{CO}^{\prime \prime \prime}{ }_{3} \mathrm{Co}\right.$ "I $\}$ cubic model (black), (ii) the polymeric network (red), (iii) the network recovered after magnetic measurement and rehydrated (blue). (c) $\chi_{M} T$ values measured at $300 \mathrm{~K}$ of a sample (polymeric network) successively hydrated and dehydrated sample; (d) $\chi_{M} T$ versus T curves of the photo-induced metastable states obtained after irradiation at $808 \mathrm{~nm}$ (see text).

FT-IR spectroscopy is a very common tool to probe the electronic state of cyanide materials, as the stretching cyanide vibrations strongly depend on the coordination mode of the cyanide ligand (bridging or terminal) and the oxidation state of the linked metal ions. ${ }^{[5,18]}$ FT-IR spectra of the pro-cube, the model cube and the polymeric material are gathered in Figures 3a. The stretching vibration located at $2162 \mathrm{~cm}^{-1}$ in the pro-cube (Figure $3 \mathrm{a}_{2}$ ) is a clear indication of the occurrence of the $\mathrm{Fe}^{\text {III }}-\mathrm{CN}-\mathrm{Co}^{\text {II }}$ linkages in this species, which is coherent with the red colour of the material. In contrast, the cyanide stretching vibration is shifted to lower wavenumbers ( $c a .2125$ and $2105 \mathrm{~cm}^{-1}$ ) that are characteristic of

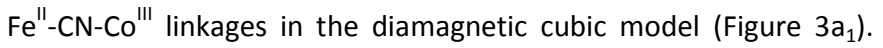
This is coherent with the occurrence of an electron transfer upon the coordination of the Tp ligand to the pro-cube and with the colour change from red to blue. When the paramagnetic cube is isolated, the IR spectrum slightly differs (see ESI) because of the presence of an additional Fe"-CN-Co" linkage that leads to a small shoulder near $2087 \mathrm{~cm}^{-1}$. The stretching vibrations in the polymeric materials allow discarding the occurrence of Fe ${ }^{\text {III }}-\mathrm{CN}-\mathrm{M}$ moieties but they are coherent with the occurrence of both $\mathrm{Fe}^{\prime \prime}-\mathrm{CN}-\mathrm{Co}^{\text {III }}$ and $\mathrm{Fe}^{\prime \prime}-$ $\mathrm{CN}-\mathrm{Co}^{\prime \prime}$ linkages. The peak appearing at $\mathrm{ca} .2050 \mathrm{~cm}^{-1}$ can be ascribed to the $\mathrm{Fe}^{\prime \prime}-\mathrm{CN}-\mathrm{CO}$ " pair while the peak centre at $2104 \mathrm{~cm}^{-1}$ corresponds to $\mathrm{Fe}^{\text {II }} \mathrm{CN}-\mathrm{Co}$ "II" pair (Figure $3 \mathrm{a}_{3}$ ). The cyanide stretching peak is broad, which could account for the presence of a distribution of environments around $\mathrm{Fe}-\mathrm{CN}$-Co bridges.

The recorded UV-vis absorption spectra of the pro-cube, cubic model and polymeric material (Figure 3) are coherent with the above-mentioned FT-IR data. The spectrum of the pro-cube (figure $3 b_{2}$ ) is dominated by a very strong high-energy cantered LigandMetal Charge Transfer (LMCT) band centred at approximately 445 $\mathrm{nm}$ and typical for the $\left[\mathrm{Fe}^{\mathrm{III}}(\mathrm{Tp})(\mathrm{CN})_{3}\right]$ complex. ${ }^{[54,40]}$ The spectrum of the model cube is notably different from the pro-cube. In its paramagnetic neutral state $\mathrm{Cs} \subset\left\{\mathrm{Fe}^{11}{ }_{4} \mathrm{Co}{ }^{\text {III }} \mathrm{Co}{ }^{\prime \prime}\right\}$, the spectrum is dominated by two broad absorption bands centred at 413 and 614 $\mathrm{nm}$ that are ascribed to a MLCT band of the $\left\{\mathrm{Fe}^{\prime \prime}(\mathrm{Tp})(\mathrm{CN})_{3}\right\}$ subunits and the Fe"-Co"' Metal-Metal Charge Transfer band (MMCT), respectively (figure $3 b_{1}$ ). As the compound gets oxidized the MMCT band notably increases and shifts to higher energy $(593 \mathrm{~nm})$. This change of the optical signature upon the conversion $\mathrm{Cs} \subset\left\{\mathrm{Fe}_{4}{ }_{4} \mathrm{CO}^{\prime \prime \prime}{ }_{3} \mathrm{CO}^{\prime \prime}\right\}$ (paramagnetic) $\rightarrow \mathrm{Cs} \subset\left\{\mathrm{Fe}_{4}{ }_{4} \mathrm{Co}{ }_{4}\right\}$ (diamagnetic) is the same as that observed with spectra recorded at controlled potential (UV-vis electrochemistry coupled experiments) in an analogue cubic complex bearing pzTp ligand instead of the Tp on the cobalt ions. ${ }^{[38]}$ Finally, the UV-vis spectrum of the polymeric material recorded in the solid-state shows a MLCT band characteristic of the $\left\{\mathrm{Fe}^{\prime \prime}(\mathrm{Tp})(\mathrm{CN})_{3}\right\}$ unit and a broad band centred at $630 \mathrm{~nm}$ (Figure $4 b_{3}$ ), similar to that observed in the cubic model complex, which is coherent with the presence of $\mathrm{Fe}^{\text {"I }} \mathrm{CN}-\mathrm{CO}$ "II pairs.

The electronic state of the pro-cube, the cubic model and the polymeric material were also probed using ${ }^{133} \mathrm{Cs}$ NMR (Figure 3c) and ${ }^{1} \mathbf{H}$ NMR (see ESI). Although the ${ }^{133} \mathrm{Cs}$ is a quadrupolar nucleus $(I=7 / 2)$, the quadrupolar constant is very weak so that well-resolved thin peaks can be obtained in solution. As demonstrated in previous studies, the inserted cation is highly sensitive to small amounts of spin-density brought by the cubic cages. ${ }^{[38,42,40]}$ Thus, ${ }^{133} \mathrm{Cs}$ NMR can be used to probe the electronic state of the molecule. Moreover, the presence of one $\mathrm{Cs}^{+}$ion per cubic unit makes the analysis quite straightforward. In the ${ }^{133} \mathrm{Cs}$ NMR a single broad peak at $c a .-720$ ppm is observed for the pro-cube in $\mathrm{CD}_{3} \mathrm{CN}$ solution (Figure $3 \mathrm{C}_{2}$ ). This value is far beyond the ${ }^{133} \mathrm{Cs}$ diamagnetic range $(+130 /-30 \mathrm{ppm}$ for $\mathrm{CsNO}_{3} \mathrm{O} 0.1 \mathrm{M}$ in $\mathrm{D}_{2} \mathrm{O}$ ) and accounts for the presence of only $\mathrm{Cs} \subset\left\{\mathrm{Fe}{ }_{4}{ }_{4} \mathrm{Co}_{4}{ }_{4}\right\}$ paramagnetic species in solution. Upon formation of the model cube by coordinating the $\mathrm{Tp}^{-}$ligand, the ${ }^{133} \mathrm{Cs} \mathrm{NMR}$ chemical shift decreases to $-232 \mathrm{ppm}$ (in $\mathrm{CD}_{2} \mathrm{Cl}_{2}$ ) but remains out of the diamagnetic range (Figure $3 \mathrm{c}_{1}$ ). This agrees with the formation of paramagnetic cubic cages with only one paramagnetic $\mathrm{Co}^{\text {"l }}$ ion, $\mathrm{Cs} \subset\left\{\mathrm{Fe}_{4}{ }_{4} \mathrm{Co}^{\mathrm{III}}{ }_{3} \mathrm{Co}{ }^{\mathrm{II}}\right\}$, as observed in previously published cubic complexes. ${ }^{[38,41]}$ If the solution is left for two days in air, a slight colour change is observed (see UV-vis data above), and the ${ }^{133} \mathrm{Cs}$ NMR signal shifts to the diamagnetic range at $c a .+50 \mathrm{ppm}$. This result fully agrees with the above-mentioned data, in particular the slow crystallization of diamagnetic cubes as seen in the XRD analysis. It is worth noting that the ${ }^{1} \mathrm{H}$ NMR spectra (shown in ESI) of the pro-cube and cubic model complex are more complicated than the ${ }^{133} \mathrm{Cs}$ ones because of the multiplicity of ${ }^{1} \mathrm{H}$ sites. However, relevant assignments have been done and are fully coherent with 
the ${ }^{133} \mathrm{Cs}$ data: a unique paramagnetic species is observed in the pro-cube solution, which first converts into a $\mathrm{Cs} \subset\left\{\mathrm{Fe}_{4}{ }_{4} \mathrm{Co}{ }_{3}{ }_{3} \mathrm{Co}\right\}$ cube upon addition of the ligand. As the solution of the model cube is left at air, the signals become diamagnetic and can be assigned to a diamagnetic cube $\mathrm{Cs} \subset\left\{\mathrm{Fe}_{4}{ }_{4} \mathrm{Co}_{4}{ }_{4}\right\}^{+}$of higher symmetry.

Concerning the polymeric material, the ${ }^{1} \mathrm{H}$ signal in the solid-state is broad because of the dipolar coupling and no relevant information can be extracted. However, the situation is much better for the solid-state ${ }^{133}$ Cs NMR spectrum, where different signals can be clearly distinguished. A signal at $+40 \mathrm{ppm}$ indicates the presence of coprecipitated $\mathrm{CsClO}_{4}$. Moreover, three signals are observed in the paramagnetic range at approximately -205, -285 and -370 ppm (Figure $3 c_{3}$ ), the last one being of weak intensity (the other small signals are ascribed to side band signals as shown in $\mathrm{SI}$ ). The regular splitting of the chemical shift of the ${ }^{133} \mathrm{Cs}$ probe could be explained by the presence of an increasing number of paramagnetic ions in the cubic units. Such behaviour is actually quite similar to that observed in our previous studies on the model Fe-Cd Prussian Blue analogues. In this work, we showed that increasing the number of paramagnetic species around a diamagnetic ${ }^{113} \mathrm{Cd}$ probe leads to an almost regular increase of the chemical shift. ${ }^{[55,56]}$ In the present case, the peaks at $-205,-285$ and $-370 \mathrm{ppm}$ can thus be tentatively assigned to the following cubic units $\mathrm{Cs} \subset\left\{\mathrm{Fe}_{4}{ }_{4} \mathrm{Co}_{3}{ }_{3} \mathrm{CO}^{\prime \prime}\right\}$, $\mathrm{Cs} \subset\left\{\mathrm{Fe}_{4}{ }_{4} \mathrm{CO}_{2}{ }_{2}{ }_{2} \mathrm{CO}_{2}{ }_{2}\right\}$ and $\mathrm{Cs} \subset\left\{\mathrm{Fe}_{4}{ }_{4} \mathrm{Co}{ }^{\prime \prime \prime} \mathrm{CO}_{3}{ }_{3}\right\}$. It is worth noticing that the presence of a high number of Co" ions in octahedral surrounding is in line with the magnetic data described below. Obviously, from a chemical point of view, the presence of Co" sites should be favoured by an incomplete substitution of the DMF solvent molecules by the Tp-Ar-Tp ligand. The latter may not replace all the coordinated DMF ligands as the compound readily precipitates when it forms. The presence of structural defects is also coherent with the amorphous nature of the material. In summary, the complementary structural and electronic analysis allows describing the polymeric material as an amorphous network made of robust cubic units in which the electronic state is controlled by the substitution of the DMF solvent molecules by the Tp-Ar-Tp ligands.

\section{Switchable electronic properties}

The magnetic measurements on the network and on the cubic molecular model were investigated in the temperature range between $2-400 \mathrm{~K}$. Figure $4(\mathrm{~b})$ shows the $\chi_{M} T$ versus $T$ curve $\left(\chi_{M}\right.$ is the molar magnetic susceptibility per $\mathrm{Fe}_{4} \mathrm{Co}_{4}$ formula unit) of the paramagnetic model cube (black curve). At $300 \mathrm{~K}$, the measured $\chi_{M} T$ value of $2.6 \mathrm{~cm}^{3} \mathrm{~mol}^{-1} \mathrm{~K}$, is coherent with the presence of one octahedral $\mathrm{Co}(\mathrm{II})$ ion per cubic unit on average $\left(\mathrm{S}=3 / 2, g_{\text {eff }}=2.8\right.$ ). The non-linearity of the $\chi_{M} T$ curve upon cooling is due to the spinorbit coupling of the octahedral $\mathrm{Co}^{\prime \prime}$ complexes as it has been well described elsewhere. ${ }^{[57]}$ More interestingly, above $300 \mathrm{~K}$ the significant increase of $\chi_{M} T$ can be ascribed to a thermally-induced electron transfer coupled to a spin transition (ETCST) on the Co(II) ion: some $\mathrm{Fe}^{\prime \prime}{ }_{\mathrm{LS}} \mathrm{COO}^{\mathrm{III}}{ }_{\mathrm{LS}}$ diamagnetic pairs being converted into $\mathrm{Fe}^{\mathrm{III}}{ }_{\mathrm{LS}}{ }^{-}$ CO" ${ }_{\text {HS }}$ paramagnetic ones (Figure $4(\mathrm{a})$ ). The transition is gradual and remains incomplete at $400 \mathrm{~K}$ (the highest available temperature in the magnetometer). The value obtained at $400 \mathrm{~K}, 4.3 \mathrm{~cm}^{3} \mathrm{~mol}^{-1} \mathrm{~K}$, suggests that approximately one FeCo pair per cube is converted on average. This estimation is based on the $\chi_{M} T$ value of the $\mathrm{Co}(\mathrm{II})$ ion measured at high temperature in a paramagnetic cube model (3.0 $\left.\mathrm{cm}^{3} \mathrm{~mol}^{-1} \mathrm{~K}\right)^{[46]}$ and the previously reported $\chi_{M} T$ value of the $\left[\mathrm{Fe}^{\mathrm{III}}(\mathrm{Tp})(\mathrm{CN})_{3}\right]^{-}$subunit. ${ }^{[58]}$ The transition is irreversible: upon cooling from $400 \mathrm{~K}$ to low temperature the $\chi_{M} T$ value slowly decreases, which can be ascribed to the spin-orbit coupling of both $\mathrm{CO}^{\prime \prime}{ }_{\mathrm{HS}}$ and $\mathrm{Fe}^{\mathrm{III}}$ LS ions (see ESI). More interestingly, a photomagnetic effect is observed on the cubic models at low temperature. Upon irradiating the diamagnetic or paramagnetic samples at $20 \mathrm{~K}$ at 808 $\mathrm{nm}\left(5 \mathrm{~mW} / \mathrm{cm}^{2}\right)$, a significant increase of magnetization occurs (see ESI), which is ascribed to an ETCST as recently demonstrated on a related compound. ${ }^{[39]}$ The overall increase of $\chi_{M} T$ value obtained after saturation, ca. 6.1 and $5.6 \mathrm{~cm}^{3} \mathrm{~mol}^{-1} \mathrm{~K}$, corresponds roughly to the conversion of 3 or 2 FeCo pairs. ${ }^{[38]}$ Figure $4 \mathrm{~d}$ show the $\chi_{M} T$ versus $T$ curve of the resulting photo-induced metastable state upon heating from $2 \mathrm{~K}$ to high temperature. The variation of the $\chi_{M} T$ value at low temperature can be to be ascribed to antiferromagnetic interactions or to the effect of the magnetic anisotropy. The decrease of the $\chi_{M} T$ value observed upon increasing the temperature (scan rate of $0.4 \mathrm{~K} / \mathrm{min}$ ), is due to the thermally-induced depopulation of the metastable state. The relaxation temperatures measured in the present experimental conditions are given by the inflexion points and correspond to $c a$. 70 and $190 \mathrm{~K}$ for the paramagnetic and diamagnetic cubic models, respectively.

The $\chi_{M} T$ versus $T$ curve of the polymeric network (Figure 4(b) red curve) shows a similar shape as that described for the molecular cube, although slight differences are observed. The $\chi_{M} T$ value measured at $300 \mathrm{~K}, 3.2 \mathrm{~cm}^{3} \mathrm{~mol}^{-1} \mathrm{~K}$, is higher than that measured for the model curve, which is coherent with the presence of a higher number of $\mathrm{CO}^{\prime \prime}$ paramagnetic ions that would arise from the presence of $\mathrm{Cs} \subset\left\{\mathrm{Fe}_{4}{ }_{4} \mathrm{CO}_{2}{ }_{2}{ }_{2} \mathrm{CO}_{2}{ }_{2}\right\}$ and $\mathrm{Cs} \subset\left\{\mathrm{Fe}_{4}{ }_{4} \mathrm{Co}^{\prime \prime \prime} \mathrm{Co}_{3}{ }_{3}\right\}$ units in the polymeric framework, as suggested above. However, a sizeable increase of $\chi_{M} T$ is clearly observed above $300 \mathrm{~K}$ and ascribed to an ETCST. The $\chi_{M} T$ value obtained at $400 \mathrm{~K}, c a .5 .3 \mathrm{~cm}^{3} \mathrm{~mol}^{-1} \mathrm{~K}$, corresponds to a partial conversion of the diamagnetic pairs into paramagnetic ones. The variation of $\chi_{M} T$ value between 300 and $400 \mathrm{~K}$ is similar to that observed in the model paramagnetic cube and corresponds roughly to a conversion rate of $35 \%$ (considering that three diamagnetic pairs could be converted per cubic units). As for the cubic model, the transition is irreversible and cannot be observed when cooling from $400 \mathrm{~K}$ (ESI). However, when the sample is dipped into water and quickly dried in air before measuring again in the magnetometer (Figure 4(b) blue curve), the ETCST transition can be recovered. This procedure has been repeated and Figure 4(c) show the approximate $\chi_{M} T$ values obtained before the magnetic measurement once the sample is hydrated and after heating at $400 \mathrm{~K}$. This is in striking contrast with the situation of the cubic model whose transition cannot be recovered after such treatment. We assume that the polymeric structure of the network and its insolubility prevents the cubic units from decoordination. The adsorption of solvents into the 
framework would thus lead back to a diamagnetic state. Such chemo-sensitive spin-state changes have already been observed in related polymeric spin-crossover compounds. ${ }^{[17,59]}$ Moreover, recent studies on FeCo ETCST molecular systems showed that interaction with solvate or small molecules inside the crystal lattice can modulate the electronic state of these systems. ${ }^{[60-62]} \mathrm{A}$ similar phenomenon is observed here, making the polymeric material a potential chemo-sensor. Finally, the photomagnetic properties of the network were also probed, however it was not possible to observed any increase of magnetization upon irradiating the sample at $808 \mathrm{~nm}$. This might be ascribed to the higher rigidity of the network that hinders the structural changes accompanying the ETCST process. ${ }^{[63]}$ 


\section{Experimental}

\section{Synthesis of the network}

The ditopic ligand and its precursors have been synthesized as in reported procedures (see details in ESI). ${ }^{8,11}$ The network has been prepared using the following procedure. To a stirred yellow solution containing $\left[\mathrm{NBu}_{4}\right]\left[\mathrm{Fe}^{\prime \prime \prime}(\mathrm{Tp})(\mathrm{CN})_{3}\right](180 \mathrm{mg}, 0.3 \mathrm{mmol})$ in $10 \mathrm{~mL}$ DMF $\mathrm{Co}\left(\mathrm{ClO}_{4}\right)_{2} \cdot 6 \mathrm{H}_{2} \mathrm{O}(90 \mathrm{mg}, 0.25 \mathrm{mmol})$ was added. The colour of the solution turned to light red. After $2 \mathrm{~min}, \mathrm{Csl}(195 \mathrm{mg}, 0.75 \mathrm{mmol})$ was added. After stirring for $2 \mathrm{~min}$ the ditopic ligand $(80 \mathrm{mg}, 0.15$ $\mathrm{mmol}$ ) was added and the resulting mixture was first sonicated and then stirred for $30 \mathrm{~min}$. A green precipitate forms right away. The mixture was then filtered and washed with DMF and hot water to yield $240 \mathrm{mg}$ of deep green solid as a product. Elemental analysis: Found: $\mathrm{C}(\%) 38.76 \mathrm{H}(\%) 3.76 \mathrm{~N}(\%)$ 24.48.Calculated for the network with 1.9 eq of ligand, $10 \mathrm{DMF}$ molecules, coprecipitated $\mathrm{CsClO}_{4} \mathrm{C}(\%)$ $38.50 \mathrm{H}(\%) 3.94 \mathrm{~N}(\%)$ 24.99 EDX analysis Fe:Co:Cs = 4:4:2.

\section{Synthesis of model cubic complex}

To a stirred solution of $\left[\mathrm{NBu}_{4}\right]\left[\mathrm{Fe}{ }^{\prime \prime \prime}(\mathrm{Tp})(\mathrm{CN})_{3}\right]$ in $2 \mathrm{~mL} \mathrm{DMF}$ (173 mg, $0.3 \mathrm{mmol}) \mathrm{Co}^{\prime \prime}\left(\mathrm{ClO}_{4}\right)_{2} \cdot 6 \mathrm{H}_{2} \mathrm{O}(108 \mathrm{mg}, 0.3 \mathrm{mmol})$ was added and the red solution stirred for 5 minutes. Then, $\mathrm{Csl}(154 \mathrm{mg}, 0.6 \mathrm{mmol})$ or $\mathrm{CsClO}_{4}(140 \mathrm{mg}, 0.6 \mathrm{mmol}$ ) in $2 \mathrm{~mL}$ DMF was added and the resulting solution stirred. After 5 minutes the ligand KTp (76 mg, $0.3 \mathrm{mmol}$ ) was added, and the greenish blue solution was stirred for 4 hours. The excess Cs-salt was separated via centrifugation and the resulting solution was precipitated with $40 \mathrm{~mL}$ ether. The resulting solid was washed with DMF/ether (1/8) and crystalized in acetonitrile and characterised by NMR.

\section{Magnetic measurements}

DC Magnetic susceptibility measurements were carried out using a Quantum Design SQUID magnetometer. The magnetic susceptibility values were corrected by subtracting the diamagnetism of the molecular constituents and of the sample holder. The sample (packed in a polyethylene bag) were introduced in the SQUID at 110 $\mathrm{K}$ under helium flow to avoid solvent loss. The magnetic field was set at 10000 Oe and the temperature sweep rate was $2 \mathrm{Kmin}^{-1}$. Photomagnetic measurements were carried out at $20 \mathrm{~K}$ on ca. 0.3 mg samples deposited as thin films.

\section{Pair distribution function}

High-energy X-ray data were collected at the 11-ID-B station at the Advanced Photon Source (Argonne National Laboratory). After corrections (background and Compton scattering), PDFs were extracted from the data using PDFgetX2 software. ${ }^{[64]}$

\section{$\mathrm{X}$-ray diffraction}

Details about X-Ray crystal structure determination are given in ESI. CCDC 2072191 contain the supplementary crystallographic data for this paper. The data can be obtained free of charge from The Cambridge Crystallographic Data Centre via www.ccdc.cam.ac.uk/structures.

\section{Other characterizations}

Technical details about FT-IR, solution and solid-state UV-vis and NMR spectroscopies, mass spectrometry, elemental analyses, thermogravimetric analyses, electronic microscopy are given in ESI.

\section{Conclusions}

In this work, we have shown that polymetallic cyanido-bridged $\left\{\mathrm{Fe}_{4} \mathrm{CO}_{4}\right\}$ molecular switches can be integrated into polymeric materials by using a stepwise molecular chemistry approach. While the chemical approach based on the use of stable pro-cube allows us to maintain the structural integrity of the cubic nodes, the rapid bond formation with the organic linkers and high insolubility of the resulting network certainly favour the precipitation of an amorphous material. As for the $\left\{\mathrm{Fe}_{4} \mathrm{CO}_{4}\right\}$ molecular model, the cubic nodes in the network material are in different electronic states. Spectroscopic evidences suggest the presence of further electronic states besides the paramagnetic and diamagnetic states observed in the model cube. This is coherent with the fact that not all solvents on the Co coordination sphere are substituted by bridging ligands. However, the thermo-induced ETCST observed in the cube was transferred to the network. More interestingly, while the phenomenon is irreversible upon heating of the molecular model, it can be retained in the polymeric materials, making this material a possible chemo sensor. At the present stage, our current research efforts are focused on (i) the exploration of related chemical approaches that are susceptible to lead to crystalline materials; and on the other hand, on (ii) the exploration of the potentialities of these materials for chemo-sensing or as intercalation materials.

\section{Conflicts of interest}

In accordance with our policy on Conflicts of interest please ensure that a conflicts of interest statement is included in your manuscript here. Please note that this statement is required for all submitted manuscripts. If no conflicts exist, please state that "There are no conflicts to declare".

\section{Acknowledgements}

This work was funded by the DIM Respore, the labex MiChem, ANR MoMa, the CNRS and Sorbonne Université. In the framework of the CNRS ЯÉCIPROCS network, this work has been accepted for synchrotron beamtime by the Soleil scientific proposal committee (BAG proposals 20191503). The authors are grateful to Pierre Fertey for his help on CRISTAL beamline at SOLEIL. The work done at the Advanced Photon Source, an Office of Science User Facility operated for the U.S. Department of Energy (DOE) Office of Science by Argonne National Laboratory, was supported by the U.S. DOE under contract no. DE-AC02-06CH11357.

\section{Notes and references}

¥ Footnotes relating to the main text should appear here. These might include comments relevant to but not central to the matter under discussion, limited experimental and spectral data, and crystallographic data.

[1] B. L. Feringa, Ed., Molecular Switches, WileyVCH-Verl, Weinheim, 2011.

[2] M. Irie, Chemical Reviews 2000, 100, 1683-1684. 
[3] W. Ke, W. Yin, Z. Zha, J. F. Mukerabigwi, W. Chen, Y. Wang, C. He, Z. Ge, Biomaterials 2018, 154, 261-274.

[4] G. Molnár, S. Rat, L. Salmon, W. Nicolazzi, A. Bousseksou, Advanced Materials 2018, 30, 1703862.

[5] P. Gütlich, H. A. Goodwin, Eds., Spin Crossover in Transition Metal Compounds I, Springer Berlin Heidelberg, Berlin, Heidelberg, 2004.

[6] P. Gütlich, H. A. Goodwin, Spin Crossover in Transition Metal Compounds II, Springer Berlin Heidelberg, Berlin, Heidelberg, 2004.

[7] P. Gütlich, H. A. Goodwin, Spin Crossover in Transition Metal Compounds III, Springer Berlin Heidelberg, Berlin, Heidelberg, 2004.

[8] M. A. Halcrow, Ed., Spin-Crossover Materials: Properties and Applications, Wiley, Chichester, 2013.

[9] A. B. Gaspar, B. Weber, in Molecular Magnetic Materials (Eds.: B. Sieklucka, D. Pinkowicz), Wiley-VCH Verlag GmbH \& Co. KGaA, Weinheim, Germany, 2016, pp. 231-252.

[10] F. Moreau, J. Marrot, F. Banse, C. Serre, A. Tissot, J. Mater. Chem. C 2020, 8, 16826-16833.

[11] M.-L. Boillot, B. Weber, Comptes Rendus Chimie 2018, 21, 1196-1208.

[12] O. Kahn, Science 1998, 279, 44-48.

[13] Y. Garcia, V. Niel, M. C. Muñoz, J. A. Real, in Spin Crossover in Transition Metal Compounds I (Eds.: P. Gütlich, H.A. Goodwin), Springer Berlin Heidelberg, Berlin, Heidelberg, 2004, pp. 229257.

[14] D. Aravena, Z. A. Castillo, M. C. Muñoz, A. B. Gaspar, K. Yoneda, R. Ohtani, A. Mishima, S. Kitagawa, M. Ohba, J. A. Real, E. Ruiz, Chem. Eur. J. 2014, 20, 12864-12873.

[15] F. J. Muñoz-Lara, A. B. Gaspar, M. C. Muñoz, A. B. Lysenko, K. V. Domasevitch, J. A. Real, Inorg. Chem. 2012, 51, 13078-13080.

[16] F. J. Muñoz-Lara, A. B. Gaspar, M. C. Muñoz, M. Arai, S. Kitagawa, M. Ohba, J. A. Real, Chem. Eur. J. 2012, 18, 8013-8018.

[17] M. Ohba, K. Yoneda, G. Agustí, M. C. Muñoz, A. B. Gaspar, J. A. Real, M. Yamasaki, H. Ando, Y. Nakao, S. Sakaki, S. Kitagawa, Angewandte Chemie International Edition 2009, 48, 47674771.

[18] C. Mathonière, European Journal of Inorganic Chemistry 2018, 2018, 248-258.

[19] Y.-S. Meng, O. Sato, T. Liu, Angewandte Chemie International Edition 2018, 57, 12216-12226.

[20] D. Aguilà, Y. Prado, E. S. Koumousi, C. Mathonière, R. Clérac, Chemical Society Reviews 2016, 45, 203-224.
[21] G. N. Newton, M. Nihei, H. Oshio, European Journal of Inorganic Chemistry 2011, 2011, 3031-3042.

[22] O. Sato, T. Iyoda, A. Fujishima, K. Hashimoto, Science 1996, 272, 704-705.

[23] V. Escax, A. Bleuzen, C. Cartier dit Moulin, F. Villain, A. Goujon, F. Varret, M. Verdaguer, Journal of the American Chemical Society 2001, 123, 12536-12543.

[24] J.-D. Cafun, G. Champion, M.-A. Arrio, C. C. dit Moulin, A. Bleuzen, Journal of the American Chemical Society 2010, 132, 11552-11559.

[25] N. Shimamoto, S. Ohkoshi, O. Sato, K. Hashimoto, Inorganic Chemistry 2002, 41, 678684.

[26] A. Bleuzen, J.-D. Cafun, A. Bachschmidt, M. Verdaguer, P. Münsch, F. Baudelet, J.-P. Itié, J. Phys. Chem. C 2008, 112, 17709-17715.

[27] J.-J. Zhang, A. Lachgar, Inorg. Chem. 2015, 54, 1082-1090.

[28] J. Zhang, A. Lachgar, J. Am. Chem. Soc. 2007, 129, 250-251.

[29] Y. V. Mironov, N. G. Naumov, K. A. Brylev, O. A. Efremova, V. E. Fedorov, K. Hegetschweiler, Angew. Chem. Int. Ed. 2004, 43, 1297-1300.

[30] L. G. Beauvais, M. P. Shores, J. R. Long, Chem. Mater. 1998, 10, 3783-3786.

[31] M. V. Bennett, M. P. Shores, L. G. Beauvais, J. R. Long, J. Am. Chem. Soc. 2000, 122, 6664-6668.

[32] M. Nihei, Y. Yanai, I.-J. Hsu, Y. Sekine, H. Oshio, Angew. Chem. Int. Ed. 2017, 56, 591-594.

[33] Y. Sekine, M. Nihei, H. Oshio, Chem. Eur. J. 2017, 23, 5193-5197.

[34] M. Nihei, Y. Yanai, D. Natke, R. Takayama, M. Kato, Y. Sekine, F. Renz, H. Oshio, Chem. Eur. J. 2019, 25, 7449-7452.

[35] D. J. Tranchemontagne, J. L. Mendoza-Cortés, M. O'Keeffe, O. M. Yaghi, Chem. Soc. Rev. 2009, 38, 1257.

[36] M. J. Kalmutzki, N. Hanikel, O. M. Yaghi, Sci. Adv. 2018, 4, eaat9180.

[37] D. Garnier, J.-R. Jiménez, Y. Li, J. von Bardeleben, Y. Journaux, T. Augenstein, E. M. B. Moos, M. T. Gamer, F. Breher, R. Lescouëzec, Chemical Science 2016, 7, 4825-4831.

[38] J.-R. Jiménez, M. Tricoire, D. Garnier, L.-M. Chamoreau, J. von Bardeleben, Y. Journaux, Y. Li, R. Lescouëzec, Dalton Trans. 2017, 46, 15549-15557.

[39] N. Daffé, J.-R. Jiménez, M. Studniarek, A. Benchohra, M.-A. Arrio, R. Lescouëzec, J. Dreiser, J. Phys. Chem. Lett. 2019, 10, 17991804. 
[40] J. Jiménez, J. Glatz, A. Benchohra, G. Gontard, L. Chamoreau, J. Meunier, A. Bousseksou, R. Lescouëzec, Angew. Chem. Int. Ed. 2020, 59, 8089-8093.

[41] D. Garnier, J.-R. Jiménez, Y. Li, J. von Bardeleben, Y. Journaux, T. Augenstein, E. M. B. Moos, M. T. Gamer, F. Breher, R. Lescouëzec, Chem. Sci. 2016, 7, 4825-4831.

[42] R. Plamont, J. Tami, J.-R. Jimenez, A. Benchohra, O. Khaled, G. Gontard, Y. Li, R. Lescouëzec, Journal of Coordination Chemistry 2018, 71, 601-614.

[43] A. Benchohra, C. Méthivier, J. Landoulsi, D. Kreher, R. Lescouëzec, Chem. Commun. 2020, 56, 6587-6589.

[44] H.-R. Wen, C.-F. Wang, Y. Song, S. Gao, J.-L. Zuo, X.-Z. You, Inorg. Chem. 2006, 45, 89428949.

[45] S. De, J.-R. Jiménez, Y. Li, L.-M. Chamoreau, A. Flambard, Y. Journaux, A. Bousseksou, R. Lescouëzec, RSC Advances 2016, 6, 1745617459.

[46] D. Li, R. Clérac, O. Roubeau, E. Harté, C. Mathonière, R. Le Bris, S. M. Holmes, Journal of the American Chemical Society 2008, 130, 252258.

[47] A. Mondal, Y. Li, M. Seuleiman, M. Julve, L. Toupet, M. Buron-Le Cointe, R. Lescouëzec, Journal of the American Chemical Society 2013, 135, 1653-1656.

[48] S. J. L. Billinge, M. G. Kanatzidis, Chem. Commun. 2004, 749.

[49] T. L. Christiansen, S. R. Cooper, K. M. Ø. Jensen, Nanoscale Adv. 2020, 2, 2234-2254.

[50] K. W. Chapman, D. F. Sava, G. J. Halder, P. J. Chupas, T. M. Nenoff, J. Am. Chem. Soc. 2011, 133, 18583-18585.

[51] C. Castillo-Blas, J. M. Moreno, I. Romero-Muñiz, A. E. Platero-Prats, Nanoscale 2020, 12, 1557715587.

[52] J. Glatz, L.-M. Chamoreau, A. Flambard, J.-F. Meunier, A. Bousseksou, R. Lescouëzec, Chem. Commun. 2020, 56, 10950-10953.

[53] M. Shatruk, C. Avendano, K. R. Dunbar, in Progress in Inorganic Chemistry (Ed.: K.D. Karlin), John Wiley \& Sons, Inc., Hoboken, NJ, USA, 2009, pp. 155-334.

[54] M. Nihei, M. Ui, N. Hoshino, H. Oshio, Inorg. Chem. 2008, 47, 6106-6108.

[55] A. Flambard, F. H. Köhler, R. Lescouëzec, Angewandte Chemie International Edition 2009, 48, 1673-1676.

[56] A. Flambard, F. H. Köhler, R. Lescouëzec, B. Revel, Chem. Eur. J. 2011, 17, 11567-11575.
[57] F. Lloret, M. Julve, J. Cano, R. Ruiz-García, E. Pardo, Inorganica Chimica Acta 2008, 361, 34323445.

[58] R. Lescouëzec, J. Vaissermann, F. Lloret, M. Julve, M. Verdaguer, Inorganic Chemistry 2002, 41, 5943-5945.

[59] M. C. Muñoz, J. A. Real, Coordination Chemistry Reviews 2011, 255, 2068-2093.

[60] C.-Q. Jiao, W.-J. Jiang, Y.-S. Meng, W. Wen, L. Zhao, J.-L. Wang, J.-X. Hu, G. G. Gurzadyan, C.Y. Duan, T. Liu, National Science Review 2018, 5, 507-515.

[61] M. Nihei, Y. Yanai, I.-J. Hsu, Y. Sekine, H. Oshio, Angew. Chem. Int. Ed. 2017, 56, 591-594.

[62] Y. Sekine, M. Nihei, H. Oshio, Chemistry - A European Journal 2017, 23, 5193-5197.

[63] L. Trinh, S. Zerdane, S. Mazérat, N. Dia, D. Dragoe, C. Herrero, E. Rivière, L. Catala, M. Cammarata, E. Collet, T. Mallah, Inorg. Chem. 2020, 59, 13153-13161.

[64] X. Qiu, J. W. Thompson, S. J. L. Billinge, J Appl Crystallogr 2004, 37, 678-678. 